\title{
DELAY IMPACT ANALYSIS METHOD FOR LOST PRODUCTIVITY IN CONSTRUCTION PROJECTS
}

\author{
Jyh-Bin Yang ${ }^{1 *}$, Kuei-Mei Huang ${ }^{2}$, Chang-Hung Lee ${ }^{3}$, and Sheue-Meei Chen ${ }^{3}$ \\ ${ }^{1}$ Graduate Institute of Construction Engineering \& Management, National Central University, Taiwan \\ ${ }^{2}$ Ph.D. Program of Technology Management, Chung Hua University, Taiwan \\ ${ }^{3}$ Department of Construction Management, Chung Hua University, Taiwan \\ *Corresponding author (jyhbin@ncu.edu.tw)
}

\begin{abstract}
Schedule delays commonly appear in construction projects and result in delay claim progressively. Several studies have proposed various schedule delay analysis methodologies. By using the as-planned and as-built schedules, most previous studies focus on the impact calculation of identified delay events on project duration. They consider the schedule variances between the as-planned and as-built schedules, but ignore to connect delay evidence to as-built schedule. Lost productivity, one essential delay cause, is usually experienced by a contractor while accomplishing its works less than planned rate of production. In a construction project, a contractor usually suffers certain damages by lost productivity caused by the owner or the third party, but the schedule impacts from the damages are not easily evaluated. How to calculate the schedule impacts by lost productivity plays a key role for solving a delay claim with lost productivity. This study tries to propose a delay analysis method for considering the schedule impact of lost productivity. With a simplified case study, the proposed method can be used as a tool to calculate the schedule impacts of schedule delays with lost productivity.
\end{abstract}

Keywords: Lost Productivity, Construction Projects, Delay Analysis, Schedule Management

\section{INTRODUCTION}

Lost productivity or loss of productivity, one essential delay cause, is usually experienced by a contractor while accomplishing its works less than planned rate of production. In a construction project, a contractor usually suffers certain damages by lost productivity caused by the owner, or the third party. In the viewpoint of a contractor, lost productivity, resulting from some actions with the owner or the third party's responsibility, may not be easily detected. How to calculate the schedule impact by lost productivity plays a key role for solving a delay claim with lost productivity.

In the construction industry, many schedule delay analysis methods have been developed [1]. By using the as-planned and as-built schedules, most previous studies focus on the impact calculation of identified delay events on project duration. They consider the schedule variances between the as-planned and as-built schedules, but ignore to connect delay evidence to as-built schedule. Namely, available delay analysis methods mainly perform delay analysis depending on surface data (as-planned and as-built schedules) rather than root delay causes. In solving the problem of schedule delay with lost productivity, there is a need to integrate lost productivity calculation and schedule delay impact calculation.

\section{EXISTING METHODS}

Many delay analysis methods are available. The most common methods include the as-planned expanded technique, collapsed but-for technique and windows delay analysis method [1]. These methods mainly calculate the schedule variances between the as-planned and as-built schedules to identify the schedule impact of delayed activity on project duration.

To help schedule analysts solving the problem of lost productivity calculation, the AACE International organizes the best practices, the Recommended Practice No. 25R-03, of estimating lost labor productivity in construction claims 
[2]. This report provides comprehensive information on lost productivity calculation, excepting the issue of schedule impact analysis of lost productivity. Lee et al. [3] has proposed a method consisting of converting the lost productivity into the delay duration and analyzing its impacts on the construction schedule delay. Notably, the approach proposed by Lee et al. focuses on the calculation of lost productivity rather than developing a delay analysis method with the ability of solving delay problem caused by lost productivity.

\section{PROPOSED APPROACH}

Integrating the as-planned expanded technique [4] and the method proposed by Lee et al. [3], this study proposes an innovative delay analysis method considering lost productivity. Main analysis steps are described as follows.

- Step 1: to collect the as-planned schedule, as-build schedule and construction daily reports.

- Step 2: to clarify whether the delayed activity has the impact of lost productivity.

- Step 3: to collect productivity-related information, including resource usage, finished item with quantity, and minutes.

- Step 4: to identify delayed schedule caused by lost productivity.

- Step 5: to calculate regular and impacted productivities.

- Step 6: to calculate impacted as-planned schedule.

- Step 7: to calculate the variance between the impacted as-planned schedule and the as-built schedule.

- Step 8: to summarize all schedule variances.

\section{TEST}

For examining the capability of proposed method, this study performs all the steps depicted previously by a real case. The test case is a road construction project which encounters a land acquisition problem. Owing to the land acquisition activity is behind its planned schedule, it results in delaying following activities, for example, drainage pipeline installation. The productivity data for different drainage pipeline activities are collected and analyzed. Compared to the as-planned schedule, the proposed method identifies that the impacted activity has 14.5 day lost productivity delay within a 15-day delay for a drainage pipeline installation activity. That is the proposed method can detect and calculate the schedule impacts of delay event with lost productivity.

\section{CONCLUSIONS}

How to calculate the schedule impacts by lost productivity plays a key role for solving a delay claim with lost productivity. Based on the as-planned expanded method and productivity calculation, this study tries to propose an innovative delay analysis method for considering the schedule impact of lost productivity. With a simplified case study, the proposed method can be used as a tool to calculate the schedule impacts while lost productivity problem occurs. This study has completed preliminary test, further study will be conducted to develop a comprehensive delay analysis method for solving the lost productivity problems a contractor might encounter.

\section{ACKNOWLEDGEMENTS}

The authors would like to thank the National Science Council, Taiwan, ROC, for financially supporting this research under Contract Nos. NSC 98-2221-E-216-046 and NSC 99-2221-E-008-111.

\section{REFERENCES}

[1] Yang, J. B. and Yin, P. C., "Isolated Collapsed But-For Delay Analysis Methodology”, Journal of Construction Engineering and Management, 135(7), 570-578, 2009.

[2] AACE International, Inc., Estimating Lost Labor Productivity in Construction Claims, AACE International Recommended Practices No.25R-03, 2004.

[3] Lee, H. S., Ryu, H. G., Yu, J. H. and Kim, J. J., "Method for Calculating Schedule Delay Considering Lost Productivity”, Journal of Construction Engineering and Management, 131(11), 1147-1154, 2005.

[4] Zack, J. G., "But-for Schedules-Analysis and Defense”, Cost Engineering, 43(8), 13-17, 2001. 